\title{
Empowering the Battered Women: The Effectiveness of a Self-Compassion Program
}

\author{
Eirini Karakasidou, Anastasios Stalikas \\ Department of Psychology, Panteion University of Social and Political Sciences, Athens, Greece \\ Email: irenekarakasidou@yahoo.com
}

How to cite this paper: Karakasidou, E., \& Stalikas, A. (2017). Empowering the Battered Women: The Effectiveness of a Self-Compassion Program. Psychology, 8, 2200-2214.

https://doi.org/10.4236/psych.2017.813140

Received: October 9, 2017

Accepted: November 26, 2017

Published: November 29, 2017

Copyright $\odot 2017$ by authors and Scientific Research Publishing Inc. This work is licensed under the Creative Commons Attribution International License (CC BY 4.0).

http://creativecommons.org/licenses/by/4.0/

(c) (i) Open Access

\begin{abstract}
Self-compassion represents an attitude that has the strength of fostering positive emotions toward oneself while simultaneously maintaining a sense of connectedness with others. Empirical work so far has provided evidence that self-compassion contributes to well-being, happiness and life satisfaction. Domestic violence may be defined as willful intimidation, physical assault, battery, sexual assault, and/or other abusive behavior-as part of a systematic pattern of power and control-perpetrated by one intimate partner against another. Domestic violence survivors often feel shame, and blame themselves for being battered. This study aimed to examine the effectiveness of a self-compassion program in increasing self-compassion and fostering psychological well-being of abused women. A sample of 21 women completed five self-report questionnaires (Self-Compassion Scale, Positive and Negative Affect Scale, Resilience Scale, Subjective Happiness Scale and Depression, Anxiety and Stress Scale) one week prior, one week following and six months after the completion of the six-week intervention program. The results indicated significant increases in self-compassion, positive affect, resilience and subjective happiness as well as decreases in negative affect depression, anxiety and stress. These findings might assist researchers and clinicians to develop future interventions in order to cultivate kind and encouraging attitudes in suffering individuals.
\end{abstract}

\section{Keywords}

Self-Compassion Program, Domestic Violence, Self-Compassion, Well Being

\section{Introduction}

Self-compassion is a concept first researched and defined by Neff (2003b) and may be operationally defined as being able to treat yourself just like you would 
treat a loved one in times of need: with kindness, warmth and acceptance. According to Neff (2003a), self-compassion consists of three elements: “a) self-kindness-being kind and understanding toward oneself in instances of pain or failure rather than being harshly self-critical, b) common humanity-perceiving one's experiences as part of the larger human experience rather than seeing them as separating and isolating, and c) mindfulness-holding painful thoughts and feelings in balanced awareness rather than over-identifying with them" (p. 85). For one to be considered self-compassionate, all three components need to be present to a certain degree (Neff, 2009).

In the recent years, self-compassion has been receiving increased attention with several studies examining its role on well-being (e.g., Hall, Row, Wuensch, \& Godley, 2013; Smeets et al., 2014). Research findings indicate positive relations between self-compassion and various aspects of well-being (Neely, Schallert, Mohammed, Roberts, \& Chen, 2009; Neff, 2003a; Neff, 2003b; Neff, Kirkpatrick, \& Rude, 2007). Specifically, self-compassion has been found to be related to higher levels of happiness, greater life-satisfaction and better emotional regulation (Barnard \& Curry, 2011). Because self-compassionate people are kind, mindful with their own pain and do not over-identify with it, but rather treat themselves with support and care, they appear to have a better cognitive reappraisal and acceptance when faced with hardship and adversity (Allen \& Leary 2010; Leary, Tate, Adams, Batts Allen, \& Hancock, 2007). Self-compassion seems to be a great asset for one's more positive sense of well-being and it appears to make people feel safer and more in peace with their doings or misdoings (Zessin, Dickhäuser, \& Garbade, 2015). Accumulating evidence suggests that self-compassion acts like an armor, protecting oneself against psychopathological symptoms (Barnard \& Curry, 2011). The process by which self-compassion protects people against stressful events is very crucial for an individual's mental health (Leary et al., 2007). According to Neff and colleagues (2007), an increase in self-compassion over a one-month period was associated with a decrease in self-criticism, depression, rumination, thought suppression and anxiety, and with an increase in feeling interpersonally connected to others. Furthermore, resilience appears to relate to the ability to be self-compassionate (Trompetter et al., 2016).

Self-criticism, thought suppression and rumination are phenomena associated with trauma symptoms (Thompson \& Waltz, 2008). Domestic violence survivors are a special population which experiences traumatic situations; very often feeling shame and blaming themselves for being battered (Turnage, Jacinto, \& Kirven, 2003). We suggest that the process of self-compassion would be benefited by reducing their self-critical view and begin to accept themselves as people worthy of love and respect. Self-compassion as a process repairs negative feelings about oneself and prepares for healthy relationships. Helping domestic violence survivors work toward self-compassion is important because such individuals tend to judge themselves more harshly than others, resulting in negative emotional consequences (Macaskill, Maltby, \& Day, 2002). 
According to the National Coalition against Domestic Violence, domestic violence is willful intimidation, physical assault, battery, sexual assault, and/or other abusive behaviors -as part of a systematic pattern of power and controlperpetrated by one intimate partner against another. It includes physical violence, sexual violence, financial abuse, threats, and emotional or psychological abuse (NCADV, 2015). While different agencies may vary in how they categorize abuse, they overwhelmingly agree that most victims experience multiple types of abuse. The frequency and severity of domestic violence varies dramatically. Domestic violence accounts for $15 \%$ of all violent crime, and is most common among women between the ages of 18 - 24 (NCADV, 2015).

Most surveys about abused women have shown specific characteristics of the woman-victim. It is reported that women who suffer abusive behavior are characterized by low self-esteem and strong dependence, characteristics that result from the belief of inadequacy. At the same time, abusive behaviors, as part of a systematic pattern of power and control behavior, give the conviction to victims that they are responsible for what is happening to them. This conviction, combined with the feeling of shame, legitimizes the victims' perception that their own ineffective behavior is responsible for their abuse (Andrews \& Brewin, 1990). Victims appear as women who have not developed the ability to exercise control over their lives and do not take measures to improve their everyday life. Furthermore, victims seem to have developed a sense of shame, thus they conceal both their physical and psychological traumas and they are socially isolated and emotionally injured. Emotional entrapment increases anxiety and depression, while in those conditions self-esteem is decreasing (Cascardi \& O'Leary, 1992). Abused women present higher levels of depression, anxiety and other psychological disorders when compared to non-abused ones (Campbell \& Lewandowski, 1997).

Considering the aforementioned about both the negative consequences of intimate violence and the positive effects of self-compassion, it becomes clear that the cultivation of self-compassion could have beneficial effects for the psychological well-being of battered women. Self-compassion intervention can be used to help those women to love themselves and relate to themselves in a healthier way. Leary and his colleagues (2007) comment that self-compassion may be particularly beneficial for people who are low in self-esteem because self- compassion offers protection against the comparison between oneself and others. Furthermore, Neff and her colleagues (2005) have found that self-compassion was negatively associated with shame and emotional exhaustion, an outcome that can be a great advantage against the shame of battered women. More recently, Gilbert and Proctor (2006) developed a program aimed at fostering compassion and decreasing shame and self-criticism in patients with personality and/or mood disorders attending a hospital day treatment program.

The present study aims to examine the effectiveness of a self-compassion program to a special population, abused women. Karakasidou and Stalikas (2017) 
have recently published a study where they found evidence of the success of a training program for teaching people to be more self-compassionate. The results of this study suggest that self-compassion is teachable and that higher levels of self-compassion are related to higher levels of positive emotions, life satisfaction and subjective happiness. Moreover, the benefits of the self-compassion program appear to be enduring, lasting at least 6 months after completion of the program. It seems that self-compassion can be used as a different road to positivity by enhancing well-being.

The specific characteristics of the women-victims create the necessity of examine the effectiveness of the Self-Compassion Program at this special population. Furthermore, we are going to examine its effect in increasing levels of positive affect, subjective happiness and resilience as well as in decreasing levels of negative affect and symptoms of depression, anxiety and stress. Last but not least the gains of the program are expected to be maintained 6 months after completion of the program.

Specifically, the research questions of this study are:

a) Is a Self-Compassion intervention program effective in raising levels of self-compassion of abused women?

b) Does the increase in self-compassion levels remain stable after the completion of the program?

c) Does the Self-Compassion intervention program lead to an increase in levels of positive affect, subjective happiness and resilience?

d) Do the increased levels of positive affect, subjective happiness and resilience remain high after 6 months?

e) Does the Self-Compassion intervention program decrease levels of negative affect, depression, anxiety and stress?

f) Do the decreased levels of negative affect, depression, anxiety and stress remain stable after 6 months?

\section{Methods}

\subsection{Participants}

The sample population in this study was comprised of 21 women who received free psychological services at a Counselling Center in Athens, through the General Secretariat for Equality policy. Subjects ranged in age from 31 to 49 years old with mean age $41.48(S D=5.98)$. All subjects were of Greek ethnicity and were unemployed. Most of the women were married (70\%), while $5 \%$ were single, $15 \%$ were divorced, $5 \%$ in a relationship, and $5 \%$ widowed. Furthermore, 20 out of 21 women had children. The present study was conducted according to the Greek Psychological Society ethical research guidelines.

\subsection{Materials}

Participants were asked to complete five self-report questionnaires one week prior, one week following and six months after the termination of the six-week 
intervention program.

The scales were:

Self-compassion Scale [(SCS) Karakasidou, Pezirkianidis, Galanakais, \& Stalikas, 2017]. Participants were given the 26-item Self-Compassion Scale. The SCS includes 6 subscales: the Self- Kindness subscale (e.g., "I try to be understanding and patient toward aspects of my personality I don't like"), the Self-Judgment subscale (e.g., "I'm disapproving and judgmental about my own flaws and inadequacies"), the Common Humanity subscale (e.g., "I try to see my failings as part of the human condition"), the Isolation subscale (e.g., "When I think about my inadequacies it tends to make me feel more separate and cut off from the rest of the world"), the Mindfulness subscale (e.g., "When something painful happens I try to take a balanced view of the situation"), and the Over-Identification subscale (e.g., "When I'm feeling down I tend to obsess and fixate on everything that's wrong."). Responses are given on a 5-point scale from "1-Almost Never" to "5-Almost Always." The Greek version of the Self-Compassion Scale did not confirm Neff's (2003) model of a higher-order single-factor structure of SCS that contains the 6 components of self-compassion. Recent evidence has shown that the different components of self-compassion are independent and do not measure a higher-order self-compassion construct (Costa et al., 2016; Williams, Dalglseih, Karl, \& Kuyken, 2014). For the purpose of this study and for a better interpretation of the results, mean scores on the six subscales were averaged (after reverse-coding negative items) to create an overall self-compassion score ranging from 26 to 130 (Neff, 2016). In the current research, internal consistency reliability was found to be $a$ $=0.88$.

Positive and Negative Affect Scale [(PANAS) Daskalou \& Sigkollitou, 2012; Watson, Clark, \& Tellegen, 1988]. The Positive and Negative Affect Scale is comprised of 20 items with two dimensions, with 10 items for positive and 10 items for negative affect (e.g. "Active", "Disturbed"), using a modified Likert-type scale, ranging from 1 (very slightly or not at all) to 5 (extremely). For each sub-scale, total scores range from 10 to 50. Higher scores demonstrate greater positive or negative affect. Internal consistency reliability in the present study was $\alpha=0.76$ for positive affect and $\alpha=0.78$ for negative affect.

Depression, Anxiety, Stress Scale [(DASS) Lovibond \& Lovibond, 1995; Lyrakos et al., 2011]. We used the DASS 21 to measure symptoms of depression, anxiety and stress. The respondents are requested to self-report on a Likert scale (0 "did not apply to me at all" to 3 "applied to me very much or most of the time"). We used the Greek standardized version of DASS 21. Internal consistency reliability in the present study was $\alpha=0.81$ for depression, $\alpha=0.75$ for anxiety and $\alpha=0.86$ for stress.

Subjective Happiness Scale [(SHS) Karakasidou, Pezirkianidis, Stalikas, \& Galanakis, 2016; Lyubomirsky \& Lepper, 1999]. The Subjective Happiness Scale was used to examine the subjectivity of the participants' global happiness. The scale uses four items rated on a 7-point Likert scale (1 "Not a very happy person" 
to 7 "A very happy person") with higher scores reflecting greater happiness (e.g., "Some people are generally very happy. They enjoy life regardless of what is going on, getting the most out of everything. To what extent does this characterization describe you?"). In our sample the scale demonstrated adequate internal consistency $(a=0.80)$.

The Connor-Davidson Resilience Scale [(CD-RISC) Connor \& Davidson, 2003; Dimitriadou \& Stalikas, 2012]

The Connor-Davidson Resilience scale (CD-RISC) is a self-report measure. It is comprised of 25 items, each rated on a 5-point Likert scale $(0-4)$, as follows: not true at all (0), rarely true (1), sometimes true (2), often true (3), and true nearly all of the time (4). The total score ranges from $0-100$, with higher scores reflecting greater resilience (e.g., "Can handle unpleasant feelings"). The CDRISC has sound psychometric properties and distinguishes between those with greater and lesser resilience. We used the Greek version of the scale, which demonstrated good internal consistency in our sample $(\alpha=0.81)$.

\subsection{Procedure}

For the purpose of this study, a consent form as well as a briefing and a debriefing statement were provided to the participants. The intervention lasted 6 weeks. During the first meeting the participants were asked to participate voluntarily in this study and were informed about the confidentiality of their data and their right to withdraw from the study at any time. All participants received a booklet consisting of a) the consent form, b) the demographic characteristics and the participants' personal code (for participants' anonymity and privacy to be secured) and c) the battery of the questionnaires. The women had been informed that the program has a psycho-educational purpose aiming at training participants in the construct of self-compassion and that six more meetings are required once a week, lasting approximately 120 minutes each. Furthermore, all participants completed a 6-month follow-up assessment.

The structure of this program was based on an already established Self-Compassion Program whose aim was to investigate the effectiveness of a self-compassion intervention and whether a self-compassion intervention can predict changes in positive and negative affect, symptoms of depression, anxiety, and stress, life satisfaction and subjective happiness (Karakasidou \& Stalikas, 2017). Each session of the program focused on a specific topic. The first meeting provided an introduction to the concept of self-compassion. During the second meeting the women focused on training to self-kindness meditation. During the third meeting the trainer facilitated participants to develop a "compassionate inner voice" through writing a self-compassion letter. In week 4 the participants were taught skills to effectively cope with challenging situations. Week 5 was centered on using self-compassion in dealing with difficult emotions. During the final session, the participants discussed general issues as, for example, how to relate with positive aspects of oneself and to create a self-compassion motto. One week later the 
participants completed the same battery of the questionnaires, which they had also completed at the beginning of the program. Finally, six months later they completed the same questionnaires in order to examine the long-term benefits of the program.

\section{Results}

Statistical analysis of the raw data collected was conducted. To answer the first research question, if this program is effective in raising levels of self-compassion of abused women, a series of two-tailed paired samples $t$-tests were employed to examine pre- and post-changes in study outcomes for our group. Our sample demonstrated statistical significant increases in self kindness $(t=-3.473, p=$ $0.003)$, common humanity $(t=-2.656, p=0.017)$, mindfulness $(t=2.821, p=$ $0.012)$ as well as in total score of self-compassion $(t=-2.626, p=0.020)$ and statistical significant decreases in self judgment $(t=2.852, p=0.012)$, isolation $(t=$ 3.733, $p=0.002)$ and over identified $(t=2.124, p=0.050)$ (Table 1 ).

To answer the second research question, we used a series of paired samples $t$ tests in order to examine whether the gains at self-compassion levels would be maintained 6 months after completion of the program. There were no significant changes (all $p$ 's $>0.05)$ neither for the total score of self-compassion $(t=1.848, p$ $=0.086)$ or for the six elements of self-compassion, self-kindness $(t=2.087, p=$ $0.054)$, self-judgment $(t=1.103, p=0.287)$, common humanity $(t=-1.557, p=$ $0.140)$, isolation $(t=-0.893, p=0.384)$, mindfulness $(t=0.864, p=0.400)$, over identified ( $t=1.801, p=0.083$ ). As the figure below reveals, we can see the mean scores of the six elements of self-compassion as well as the total score of

Table 1. Pretest and Posttest Mean Scores by SC Intervention Effects Analyzed With twotailed paired samples t-test.

\begin{tabular}{cccc}
\hline & Pre test & Post test & \multirow{2}{*}{$t$} \\
\cline { 2 - 3 } & $M(S D)$ & $M(S D)$ & \\
\hline Self kindness & 11.06 & 14.12 & $-3.473^{* *}$ \\
& $(4.55)$ & $(4.66)$ & \\
Self judgment & 18.38 & 16.38 & $2.852^{\star}$ \\
& $(4.24)$ & $(5.41)$ & \\
Common humanity & 9.82 & 11.82 & $-2.656^{*}$ \\
& $(3.64)$ & $(4.17)$ & \\
Isolation & 14.94 & 12.76 & $3.733^{* *}$ \\
& $(3.61)$ & $(3.32)$ & \\
Mindfulness & 12.22 & 14.39 & $2.821^{*}$ \\
& $(4.07)$ & $(2.64)$ & \\
Over identified & 18.18 & 13.59 & $2.124^{*}$ \\
& $(3.83)$ & $(4.49)$ & \\
Self-Compassion & 61.93 & 72.00 & $-2.626^{*}$ \\
\hline
\end{tabular}

${ }^{*} p<0.05,{ }^{* *} p<0.01$. 
self-compassion after the completion of the program and six months later (see Figure 1).

In order to examine the third research question, "Does a self-compassion program lead to increase in levels of positive affect, subjective happiness and resilience?", we conducted a series of paired samples $t$ tests. Our sample demonstrated statistically significant increases in every positive variable: positive affect $(t$ $=-3.097, p=0.007)$, subjective happiness $(t=-2.380, p=0.029)$ and resilience $(t$ $=-4.707, p=0.000)$. Furthermore, to answer the fourth research question about the gains of the program we conducted a series of paired samples $t$ tests. The results showed that the levels of positive affect, subjective happiness and resilience remain stable six months after the completion of the program (Figure 2).

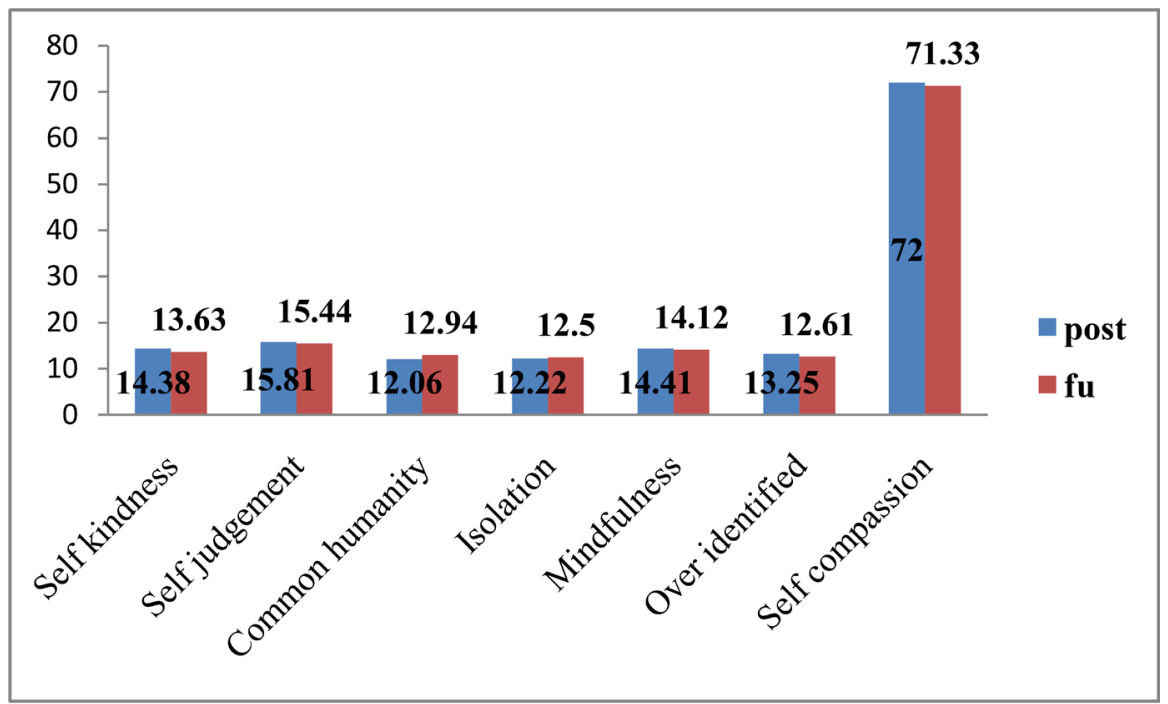

Figure 1. Elements of self-compassion after the completion of the Self-Compassion Program and 6 months later.

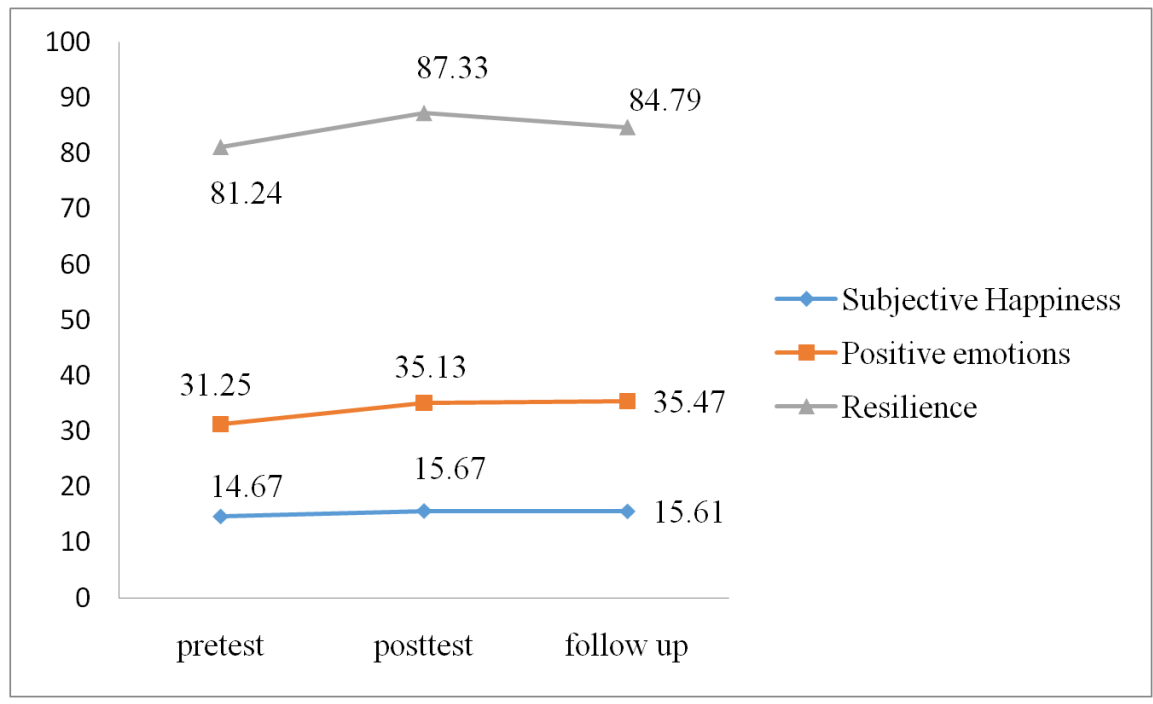

Figure 2. Positive affect, subjective happiness and resilience levels before, after and 6 months later the Self-Compassion Program. 


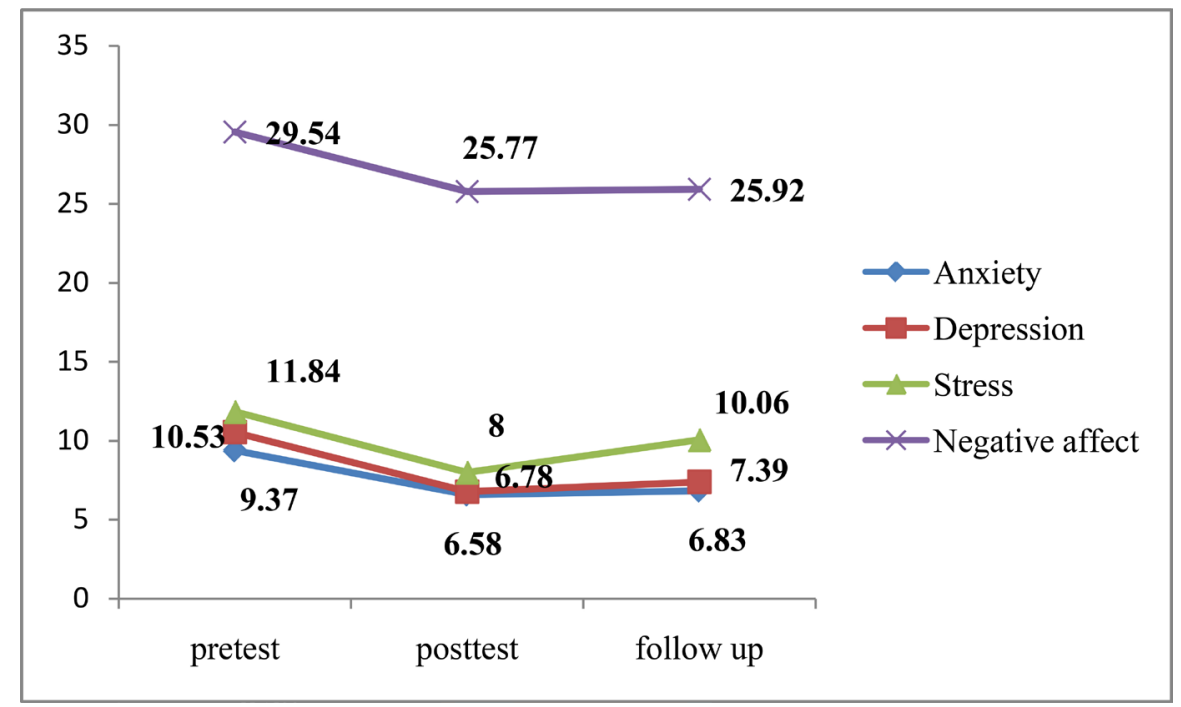

Figure 3. Negative affect, depression, anxiety and stress levels before, after and 6 months later the Self Compassion Program.

In order to test the fifth research question "Does self compassion program decrease levels of negative affect, depression, anxiety and stress", a series of paired samples $t$ tests were conducted. There were statistically significant decreases in every negative variable: negative affect $(t=2.664, p=0.021)$, depression $(t=$ $3.128, p=0.006)$, anxiety $(t=2.685, p=0.015)$ and stress $(t=3.839, p=0.001)$. Furthermore, answering the last research question about the changes at the levels of negative affect, depression, anxiety and stress, a series of paired sample $t$ tests were conducted. According to the results there were no significant changes $(p$ s $>0.05)$ for negative affect and levels of depression and anxiety 6 months after the completion of the program. On the other hand, there was a significant increase of the stress levels $(t=-4.773, p=0.000) 6$ months after the completion of the program; almost reaching the pre-intervention levels (Figure 3).

\section{Discussion}

This study aimed in examining the effectiveness of a self-compassion program in increasing self-compassion in battered women. Furthermore, we examine its effect in increasing the levels of positive affect, subjective happiness and resilience and in lowering levels of negative affect and symptoms of depression, anxiety and stress. Finally, we examined if the gains of this program remained stable 6 months after the completion of the program.

Answering our first research question, the results of this study indicated that training women, victims of trauma, to treat themselves in a more self-compassionate way resulted in significant gains in self-compassion. Previous studies demonstrated that self-compassion is a challenge as well as an opportunity for people that deal with trauma (Germer \& Neff, 2013). Self-compassion seems that cuts through the pain of the present as it opens the pain of the past. Furthermore, our 
results confirm previous assertions (Albertson, Neff, \& Dill-Shackleford, 2015; Gilbert \& Irons, 2004; Karakasidou \& Stalikas, 2017; Neff \& Costigan, 2014; Shapira \& Mongrain, 2010; Smeets et al., 2014) arguing that self-compassion can be cultivated through intervention programs.

According to our results, the levels of positive affect, subjective happiness and resilience remained stable 6 months later in accordance with our expectations. A number of positive interventions have successfully helped people learn skills in order to be happier, however, the long-term effects of these interventions are under controversy (Cohn \& Frederickson, 2010). Self-compassion is a useful tool in order to smooth pain. Everyone has a hardwired capacity to respond to their own suffering in a soothing, healing way. Women victims of domestic violence are a sensitive population and may learn a lot from things through this program.

Furthermore, in line with our expectations and answering the third research question, the results of this study strongly indicated that this self-compassion program led to an important increase in positive affect levels (Heffernan, Griffin, McNulty, \& Fitzpatrick, 2010; Hollis-Walker \& Colosimo, 2011; Neff, 2009; Neff, Rude, \& Kirkpatrick, 2007). Cultivating self-compassion may be related to how people perceive and evaluate their life and how they give meaning to it. In general, positive emotions help people recognize the positive elements in their daily life, change their focus from negative to positive and broaden their perspectives (Fredrickson, 2001; Fredrickson \& Branigan, 2005). Along with increasing levels of positive affect, this intervention significantly enhanced subjective levels of happiness. As previous results had shown (Neely et al., 2009; Seligowski, Miron, \& Orcutt, 2015; Van Dam, Sheppard, Forsyth, \& Earleywine, 2011; Wei et al., 2011; Yang, 2016), raising levels of self compassion seem to positively alter the way one evaluates his subjective happiness. Another important aspect of mental health is psychological resilience. The results of this study indicated that cultivating self-compassion may increase levels of psychological resilience. Because of the lack of studies which examine the relationship between self-compassion and resilience, our results cannot be conclusive. Nevertheless, because of the fact that self-compassion is an adaptive way of relating to the self when considering personal inadequacies or difficult life circumstances, it seems that self-compassion relates positively to resilience (Neff \& McGehee, 2010). It is very important to highlight that building resilience is a complex process and many treatments and interventions are necessary in order to make people more resilient (Southwick, Pietrzak, \& White, 2011).

In line with our expectations and answering the fifth research question of our study, the results strongly indicated that the self-compassion program can lead to statistically significant decreases in symptoms of depression, anxiety and stress (Choi, Lee, \& Lee, 2014; Leary et al., 2007), as well as to a decrease in negative affect levels (Choi, Lee, \& Lee, 2014; Leary et al., 2007). The decreased levels of negative affect, depression and anxiety were maintained 6 months after completion of the program, as we expected, but the symptoms of stress seemed to 
come back to pre-intervention levels. This is an expected result because the majority of the women are still living in a violent environment and are struggling not only with the memories, but also a difficult reality.

Self-compassion can be used as a different way to positivity by enhancing well being and reducing negative aspects of mental health. Last but not least the importance of this program is not only the cultivation of a healthier way towards oneself but also the different perspective of everyday life and the way that each one chooses to treat himself/herself when he/she is suffering. Self-compassion seems to have a protective role in highly challenging and stressful situations. Finally, the capacity to extract meaning from adverse situations and from life in general is one of the most important skills (Southwick et al., 2005) and cultivating self-compassion may help people commit to a more valued purpose.

The limitations of this study offer important directions for future research. First of all, the research was based on women, whose ethnic composition was $100 \%$ Greek and they are all unemployed. Thus, our results might not be generalizable to other groups and populations with different characteristics (e.g. different ethnic and cultural backgrounds). The current research was conducted using self-report scales, so common method variance may have impacted results (Podsakoff, MacKenzie, Lee, \& Podsakoff, 2003). It would be interesting to use a combination of quantitative and qualitative data in order to explore this concept holistically.

Positive psychology has argued that it is necessary to consider well-being not only in terms of the absence of psychopathology, but also in terms of human strengths and potentials (Seligman \& Csikzentmihalyi, 2000). Self-compassion is an important human strength as it invokes qualities of kindness, equanimity, and feelings of inter-connectedness, helping individuals to find meaning when faced with the difficulties of life. Approaching painful feelings with self-compassion is linked to a happier, more optimistic mindset, and appears to facilitate the ability to grow, explore, and understand oneself and others.

Overall, the results of this study indicate that this program works for this special population. We should remember that domestic violence has severe emotional and physical implications for women. According to the results, the participation of this program increases not only self-compassion but also increases levels of positive affect, subjective happiness and resilience and decreases levels of negative affect, depression, anxiety and stress. Also, some effects remain 6 months later, offering indications to claim that self-compassion is a very useful tool, which can be learned but needs to be exercised. It needs continuously effort and practice but it is worthy.

\section{References}

Albertson, E. R., Neff, K. D., \& Dill-Shackleford, K. E. (2015). Self-Compassion and Body Dissatisfaction in Women: A Randomized Controlled Trial of a Brief Meditation Intervention. Mindfulness, 6, 444-454. https://doi.org/10.1007/s12671-014-0277-3

Allen, A. B., \& Leary, M. R. (2010). Self-Compassion, Stress, and Coping. Social and Per- 
sonality Psychology Compass, 4, 107-118.

https://doi.org/10.1111/j.1751-9004.2009.00246.x

Andrews, B., \& Brewin, C. R. (1990). Attributions of Blame for Marital Violence: A Study of Antecedents and Consequences. Journal of Marriage and Family, 52, 757-767. https://doi.org/10.2307/352940

Barnard, L. K., \& Curry, J. F. (2011). Self-Compassion: Conceptualizations, Correlates, \& Interventions. Review of General Psychology, 15, 289-303. https://doi.org/10.1037/a0025754

Campbell, J. C., \& Lewandowski, L. A. (1997). Mental and Physical Health Effects of Intimate Partner Violence on Women and Children. Psychiatric Clinics of North America, 20, 353-374. https://doi.org/10.1016/S0193-953X(05)70317-8

Cascardi, M., \& O’Leary, K. D. (1992). Depressive Symptomatology, Self-Esteem, and Self-Blame in Battered women. Journal of Family Violence, 7, 249-259. https://doi.org/10.1007/BF00994617

Choi, Y. M., Lee, D. G., \& Lee, H. K. (2014). The Effect of Self-Compassion on Emotions When Experiencing a Sense of Inferiority across Comparison Situations. ProcediaSocial and Behavioral Sciences, 114, 949-953. https://doi.org/10.1016/j.sbspro.2013.12.813

Cohn, M. A., \& Fredrickson, B. L. (2010). In Search of Durable Positive Psychology Interventions: Predictors and Consequences of Long-Term Positive Behavior Change. The Journal of Positive Psychology, 5, 355-366. https://doi.org/10.1080/17439760.2010.508883

Connor, K. M., \& Davidson, J. R. (2003). Development of a New Resilience Scale: The Connor-Davidson Resilience Scale (CD-RISC). Depression and Anxiety, 18, 76-82. https://doi.org/10.1002/da.10113

Costa, J., Marôco, J., Pinto-Gouveia, J., Ferreira, C., \& Castilho, P. (2016). Validation of the Psychometric Properties of the Self Compassion Scale. Testing the Factorial Validity and Factorial Invariance of the Measure among Borderline Personality Disorder, Anxiety Disorder, Eating Disorder and General Populations. Clinical Psychology \& Psychotherapy, 23, 460-468. https://doi.org/10.1002/cpp.1974

Daskalou, \& Sigkollitou. (2012). Positive and Negative Affect Scale (PANAS). In A. Stalikas, S. Triliva, \& P. Roussi (Eds.), Psychometric Instruments in Greece (2nd ed., p. 526). Athens: Pedio.

Dimitriadou, D., \& Stalikas, A. (2012). Connor-Davidson Resilience Scale (CD-RISC). In A. Stalikas, S. Triliva, \& P. Roussi (Eds.), Psychometric Instruments in Greece (2nd ed., p. 717). Athens: Pedio.

Fredrickson, B. L. (2001). The Role of Positive Emotions in Positive Psychology: The Broaden-and-Build Theory of Positive Emotions. American Psychologist, 56, 218-226. https://doi.org/10.1037/0003-066X.56.3.218

Fredrickson, B. L., \& Branigan, C. (2005). Positive Emotions Broaden the Scope of Attention and Thought-Action Repertoires. Cognition \& Emotion, 19, 313-332. https://doi.org/10.1080/02699930441000238

Germer, C. K., \& Neff, K. D. (2013). Self Compassion in Clinical Practice. Journal of Clinical Psychology, 69, 856-867. https://doi.org/10.1002/jclp.22021

Gilbert, P., \& Proctor, S. (2006). Compassionate Mind Training for People with High Shame and Self-Criticism: Overview and Pilot Study of a Group Therapy Approach. Clinical Psychology and Psychotherapy, 13, 353-379. https://doi.org/10.1002/cpp.507

Gilbert, P., \& Irons, C. (2004). A Pilot Exploration of the Use of Compassionate Images in 
a Group of Self-Critical People. Memory, 12, 507-516.

https://doi.org/10.1080/09658210444000115

Hall, C. W., Row, K. A., Wuensch, K. L., \& Godley, K. R. (2013). The Role of Self-Compassion in Physical and Psychological Well-Being. The Journal of Psychology, 147, 311-323. https://doi.org/10.1080/00223980.2012.693138

Heffernan, M., Quinn Griffin, M. T., McNulty, S. R., \& Fitzpatrick, J. J. (2010). Self-Compassion and Emotional Intelligence in Nurses. International Journal of Nursing Practice, 16, 366-373. https://doi.org/10.1111/j.1440-172X.2010.01853.x

Hollis-Walker, L., \& Colosimo, K. (2011). Mindfulness, Self-Compassion, and Happiness in Non-Meditators: A Theoretical and Empirical Examination. Personality and Individual Differences, 50, 222-227.

Karakasidou, E., Pezirkianidis, C., Galanakis, M., \& Stalikas, A. (2017). Validity, Reliability and Factorial Structure of the Self Compassion Scale in the Greek Population. Jour nal of Psychology and Psychotherapy, 7, 313.

Karakasidou, E., Pezirkianidis, C., Stalikas, A., \& Galanakis, M. (2016). Standardization of the Subjective Happiness Scale (SHS) in a Greek Sample. Psychology, 7, 1753-1765. https://doi.org/10.4236/psych.2016.714164

Karakasidou, E., \& Stalikas, A. (2017). Empowering the Battered Women: The Effectiveness of a Self-Compassion Program. Psychology. Psychology, 8, 538-549. https://doi.org/10.4236/psych.2017.84034

Leary, M. R., Tate, E. B., Adams, C. E., Batts Allen, A., \& Hancock, J. (2007). Self-Compassion and Reactions to Unpleasant Self-Relevant Events: The Implications of Treating Oneself Kindly. Journal of Personality and Social Psychology, 92, 887-904. https://doi.org/10.1037/0022-3514.92.5.887

Lovibond, P. F., \& Lovibond, S. H. (1995). The Structure of Negative Emotional States: Comparison of the Depression Anxiety Stress Scales (DASS) with the Beck Depression and Anxiety Inventories. Behaviour Research and Therapy, 33, 335-343.

Lyrakos, G. N., Arvaniti, C., Smyrnioti, M., \& Kostopanagiotou, G. (2011). P03-561-Translation and Validation Study of the Depression Anxiety Stress Scale in the Greek General Population and in a Psychiatric Patient's Sample. European Psychiatry, 26, 1731.

Lyubomirsky, S., \& Lepper, H. S. (1999). A Measure of Subjective Happiness: Preliminary Reliability and Construct Validation. Social Indicators Research, 46, 137-155. https://doi.org/10.1023/A:1006824100041

Macaskill, A., Maltby, J., \& Day, L. (2002). Forgiveness of Self and Others and Emotional Empathy. The Journal of Social Psychology, 142, 663-665. https://doi.org/10.1080/00224540209603925

National Coalition against Domestic Violence (2015). What Is Domestic Violence? http://www.ncadv.org/need-support/what-is-domestic-violence

Neely, M. E., Schallert, D. L., Mohammed, S. S., Roberts, R. M., \& Chen, Y. J. (2009). Self-Kindness When Facing Stress: The Role of Self-Compassion, Goal Regulation, and Support in College Students' Well-Being. Motivation and Emotion, 33, 88-97. https://doi.org/10.1007/s11031-008-9119-8

Neff, K. D. (2003a). The Development and Validation of a Scale to Measure Self-Compassion. Self and Identity, 2, 223-250. https://doi.org/10.1080/15298860309027

Neff, K. D. (2003b). Self Compassion: An Alternative Conceptualization of a Healthy Attitude toward Oneself. Self and Identity, 2, 85-102. https://doi.org/10.1080/15298860309032

Neff, K. D. (2009). The Role of Self-Compassion in Development: A Healthier Way to 
Relate to Oneself. Human Development, 52, 211-214. https://doi.org/10.1159/000215071

Neff, K. D. (2016). The Self-Compassion Scale Is a Valid and Theoretically Coherent Measure of Self-Compassion. Mindfulness, 7, 264-274. https://doi.org/10.1007/s12671-015-0479-3

Neff, K. D., \& Costigan, A. P. (2014). Self-Compassion, Well-Being, and Happiness. Psychologie in Österreich, 2, 114-119.

Neff, K. D., Hsieh, Y. P., \& Dejitterat, K. (2005). Self-Compassion, Achievement Goals, and Coping with Academic Failure. Self and Identity, 4, 263-287. https://doi.org/10.1080/13576500444000317

Neff, K. D., Kirkpatrick, K. L., \& Rude, S. S. (2007). Self-Compassion and Adaptive Psychological Functioning. Journal of Research in Personality, 41, 139-154.

Neff, K. D., \& McGehee, P. (2010). Self-Compassion and Psychological Resilience among Adolescents and Young Adults. Self and Identity, 9, 225-240. https://doi.org/10.1080/15298860902979307

Neff, K. D., Rude, S. S., \& Kirkpatrick, K. L. (2007). An Examination of Self-Compassion in Relation to Positive Psychological Functioning and Personality Traits. Journal of Research in Personality, 41, 908-916.

Podsakoff, P. M., MacKenzie, S. B., Lee, J. Y., \& Podsakoff, N. P. (2003). Common Method Biases in Behavioral Research: A Critical Review of the Literature and Recommended Remedies. Journal of Applied Psychology, 88, 879-903.

https://doi.org/10.1037/0021-9010.88.5.879

Seligman, M. E. P., \& Csikszentmihalyi, M. (2000). Positive Psychology: An Introduction. American Psychologist, 55, 5-14. https://doi.org/10.1037/0003-066X.55.1.5

Seligowski, A. V., Miron, L. R., \& Orcutt, H. K. (2015). Relations among Self-Compassion, PTSD Symptoms, and Psychological Health in a Trauma-Exposed Sample. Mindfulness, 6, 1033-1041. https://doi.org/10.1007/s12671-014-0351-x

Shapira, L. B., \& Mongrain, M. (2010). The Benefits of Self-Compassion and Optimism Exercises for Individuals Vulnerable to Depression. The Journal of Positive Psychology, 5, 377-389. https://doi.org/10.1080/17439760.2010.516763

Smeets, E., Neff, K., Alberts, H., \& Peters, M. (2014). Meeting Suffering with Kindness: Effects of a Brief Self Compassion Intervention for Female College Students. Journal of Clinical Psychology, 70, 794-807. https://doi.org/10.1002/jclp.22076

Southwick, S. M., Pietrzak, R. H., \& White, G. (2011). Interventions to Enhance Resilience and Resilience-Related Constructs in Adults. In S. M. Southwick, B. T. Litz, D. Charney, \& M. J. Friedman (Eds.), Resilience and Mental Health: Challenges across the Lifespan (pp. 289-306). Cambridge: Cambridge University Press. https://doi.org/10.1017/CBO9780511994791.022

Southwick, S. M., Vythilingam, M., \& Charney, D. S. (2005). The Psychobiology of Depression and Resilience to Stress: Implications for Prevention and Treatment. Annual Review of Clinical Psychology, 1, 255-291. https://doi.org/10.1146/annurev.clinpsy.1.102803.143948

Thompson, B. L., \& Waltz, J. (2008). Self-Compassion and PTSD Symptom Severity. Journal of Traumatic Stress, 21, 556-558. https://doi.org/10.1002/jts.20374

Trompetter, H. R., Bohlmeijer, E. T., Lamers, S. M. A., \& Schreurs, K. M. G. (2016). Positive Psychological Wellbeing Is Required for Online Self-Help Acceptance and Commitment Therapy for Chronic Pain to Be Effective. Frontiers in Psychology, 7, 353. https://doi.org/10.3389/fpsyg.2016.00353 
Turnage, B. F., Jacinto, G. A., \& Kirven, J. (2003). Reality Therapy, Domestic Violence Survivors, and Self-Forgiveness. International Journal of Reality Therapy, 22, 24-27.

Van Dam, N. T., Sheppard, S. C., Forsyth, J. P., \& Earleywine, M. (2011). Self-Compassion Is a Better Predictor than Mindfulness of Symptom Severity and Quality of Life in Mixed Anxiety and Depression. Journal of Anxiety Disorders, 25, 123-130.

Watson, D., Clark, L. A., \& Tellegen, A. (1988). Development and Validation of Brief Measures of Positive and Negative Affect: The PANAS Scales. Journal of Personality and Social Psychology, 54, 1063-1070. https://doi.org/10.1037/0022-3514.54.6.1063

Wei, M., Liao, K. Y. H., Ku, T. Y., \& Shaffer, P. A. (2011). Attachment, Self Compassion, Empathy, and Subjective Well-Being among College Students and Community Adults. Journal of Personality, 79, 191-221. https://doi.org/10.1111/j.1467-6494.2010.00677.x

Williams, M. J., Dalgleish, T., Karl, A., \& Kuyken, W. (2014). Examining the Factor Structures of the Five Facet Mindfulness Questionnaire and the Self-Compassion Scale. Psychological Assessment, 26, 407. https://doi.org/10.1037/a0035566

Yang, X. (2016). Self-Compassion, Relationship Harmony, versus Self-Enhancement: Different Ways of Relating to Well-Being in Hong Kong Chinese. Personality and Individual Differences, 89, 24-27.

Zessin, U., Dickhäuser, O., \& Garbade, S. (2015). The Relationship between Self Compassion and Well Being: A Meta Analysis. Applied Psychology: Health and Well Being, 7, 340-364. https://doi.org/10.1111/aphw.12051 